\title{
Psychology

\section{An experimental test of self-theories of ability in youth sport}

\author{
Christopher M. Spray ${ }^{\mathrm{a}, *}$, C.K. John Wang ${ }^{\mathrm{b}}$, Stuart J.H. Biddle ${ }^{\mathrm{a}}$, \\ Nikos L.D. Chatzisarantis ${ }^{c}$, Victoria E. Warburton ${ }^{\mathrm{a}}$ \\ ${ }^{\mathrm{a}}$ School of Sport and Exercise Sciences, Institute of Youth Sport, Loughborough University, \\ Loughborough, Leicestershire LE11 3TU, UK \\ ${ }^{\mathrm{b}}$ Department of Physical Education and Sports Science, National Institute of Education, \\ 1 Nanyang Walk, Singapore 637616, Singapore \\ 'School of Sport and Health Sciences, University of Exeter, St Luke's Campus, Exeter EX1 2LU, UK \\ Received 1 September 2004; received in revised form 10 December 2004; accepted 10 May 2005 \\ Available online 19 September 2005
}

\begin{abstract}
Objectives: The purpose of this study was to examine causal links between implicit beliefs about sport ability and situational achievement goals among 123 secondary school students (54 males, 69 females; mean age $=13.40$ years, $\mathrm{SD}=1.18$ ) from one school in the English Midlands. Cognitive, affective, and behavioural indicators were assessed to test for differences between two experimental groups (entity-induced and incremental-induced beliefs) and a control group in the face of achievement setbacks.

Method: Field experiment.

Results: Support was found for a causal link between sport ability beliefs and achievement goals both before and after failure on a sport task. Ability attributions for failure were stronger for entity theorists but there were no differences between groups on affective reactions and willingness to participate in a future training programme, probably due to high incremental beliefs in all participants.

Conclusion: Discussion centres on the links between entity and incremental beliefs, achievement goals and motivational outcomes in youth sport. Moreover, implications for future studies that seek to manipulate individuals' sport ability beliefs are examined.
\end{abstract}

(C) 2005 Elsevier Ltd. All rights reserved.

Keywords: Affect; Attributions; Entity; Incremental; Learning goal; Performance goal; Youth sport

\footnotetext{
* Corresponding author. Tel.: +44 1509 226339; fax: +44 1509226301.

E-mail address: c.m.spray@lboro.ac.uk (C.M. Spray).
} 
Motivation is a central topic in general psychology (Weiner, 1992) as well as sport and exercise psychology (Biddle, 1997; Roberts, 2001), and theoretical perspectives on motivation are numerous. When studying youth in sport and physical education contexts, a social-cognitive perspective has become dominant in the past decade or so. In particular, sport psychologists have enthusiastically embraced the tenets of achievement goal theory (Duda, 2001; Duda \& Hall, 2001; Roberts, 2001). At the same time, other theoretical approaches have been proposed that appear to be conceptually related to achievement goal theory, and researchers have advocated testing the conceptual convergence of achievement goal theory with these complementary perspectives (Roberts, 1992; Wang \& Biddle, 2001). For example, Dweck and her colleagues argue persuasively for the utility of examining self-theories of ability and goals in the achievement domain (see Dweck, 1999). Therefore, the purpose of the present investigation is to examine the links between self-theories of ability and achievement goals in determining young people's motivation in sport.

Self-theories of ability are part of individuals' 'implicit theories' regarding their beliefs about the stability or malleability of human attributes and behaviours. Implicit theories have been examined extensively in the educational achievement domain, and more recently, in terms of personality, social judgement and interpersonal relationships (see Dweck, 1999; Dweck, Chiu, \& Hong, 1995a,b; Dweck \& Leggett, 1988; Franiuk, Cohen, \& Pomerantz, 2002; Hong, Chiu, Dweck, Lin, \& Wan, 1999; Levy \& Dweck, 1998; Levy, Stroessner, \& Dweck, 1998; McConnell, 2001; Plaks, Stroessner, Dweck, \& Sherman, 2001; Spinath, Spinath, Riemann, \& Angleitner, 2003). Across domains, support has been found for the existence of 'entity' and 'incremental' beliefs. An entity belief endorses the view that a personal attribute (such as intelligence) is fixed and cannot be improved, or that a behaviour (self or another's) reflects trait-based qualities that are stable. An incremental belief, on the other hand, reflects the view that personal attributes are increasable through learning, or that behaviour is more contextrelated and influenced by mediating processes (Levy \& Dweck, 1998). Although it is accepted that people can hold both beliefs to different degrees, one theory or set of beliefs is likely to be dominant (Dweck et al., 1995b). Participants in research studies are, therefore, classified as 'entity theorists' or as 'incremental theorists' depending on their responses to measures of existing beliefs in a specific domain such as intelligence or morality. In experimental work, participants are assigned to either an entity or incremental condition which attempts to (temporarily) manipulate their implicit theories (Dweck, 1999). This method of inquiry would suggest that individuals' implicit theories are themselves malleable.

In her original motivational model in the educational achievement domain, Dweck argued that entity and incremental beliefs orient an individual toward different achievement goals (Dweck \& Elliott, 1983; Dweck \& Leggett, 1988). Specifically, her research showed clearly that children possessing an entity theory of intelligence were more likely to adopt a performance achievement goal (a goal based on demonstrating success in normatively comparative terms). Conversely, children possessing an incremental theory of intelligence were more likely to adopt a learning goal (a goal based on developing success in self-referent terms, such as personal improvement). Dweck (1999) has proposed that "an entity theory, with its idea of fixed intelligence, should make students concerned with showing they're smart and so should foster performance goals" (p. 20). Conversely, "an incremental theory, with its idea of malleable intelligence, should make students concerned with getting smarter and so should promote learning goals" (p. 20).

Researchers have begun to examine self-theories in the physical domain with respect to individuals' beliefs about the malleability and stability of athletic ability. For example, initial experimental studies provided evidence that self-efficacy and perceptual-motor performance are more positively affected by conceptions of ability associated with acquirable skill than when ability is 
viewed as inherent aptitude (Jourden, Bandura, \& Banfield, 1991), and that in the face of difficulty, higher motivation and self-efficacy and less negative affect towards exercise are found for individuals who are told that athletic co-ordination is mostly learned compared to participants who are told that athletic co-ordination is genetically determined (Kasimatis, Miller, \& Macussen, 1996). Although utilising an experimental design, these studies failed to assess the efficacy of the belief manipulations in creating entity and incremental conditions. Moreover, they did not determine links between participants' beliefs about ability and achievement goals.

Investigations into the links between self-theories of beliefs and achievement goals in the physical domain have invariably adopted a cross-sectional correlational approach. Moreover, the focus of these studies has been on goal orientations or individuals' tendency to adopt performance or learning goals. For example, Biddle, Soos, and Chatzisarantis (1999) tested a model predicting children's intention to participate in sport from perceived competence, goal orientations, and ability beliefs. They found that for Hungarian youth, entity beliefs predicted an ego (performance) goal orientation, and incremental beliefs predicted a task (learning) orientation. Similar findings have emerged in sport- and physical educationbased research (Biddle, Wang, Chatzisarantis, \& Spray, 2003; Cury, Da Fonseca, Rufo, \& Sarrazin, 2002; Lintunen, Valkonen, Leskinen, \& Biddle, 1999; Ommundsen, 2001a,b; Sarrazin et al., 1996). This line of inquiry has led to the development of a measure to assess people's naturally occurring beliefs about ability in sport - the Conceptions of the Nature of Athletic Ability Questionnaire Version 2 (CNAAQ-2; Biddle et al., 2003). Selected items from the CNAAQ-2 were used in the present study to assess the efficacy of the incremental and entity belief manipulations.

In addition to linking self-theories of ability to goals, motivational researchers also need to test whether children differing in entity and incremental beliefs show different cognitive, affective and behavioural responses. For example, Dweck (1999) predicts more negative outcomes for entity theorists in comparison to incremental theorists under conditions of failure. This is because those holding strong entity beliefs will doubt their (stable) ability after failure whereas those with incremental beliefs will see failure as a temporary setback that is caused by mediating processes that can be rectified, such as an incorrect strategy or low effort. Consequently, we would expect more negative affective reactions after failure from entity theorists because a stable attribute or quality has been documented as weak. In addition, we would expect attributions to low ability (a fixed trait) to be more likely for those holding entity beliefs and attributions to low effort (a mediating process) to be more likely for incremental theorists (Hong et al., 1999; Levy \& Dweck, 1998). In terms of behavioural differences, entity theorists are predicted to be less likely to seek ways of improving their (low) ability. This should lead to a tendency to reject opportunities for learning and improvement provided by training programmes (Dweck, 1999; Dweck \& Leggett, 1988).

This experiment, therefore, examined the causal relationships between young people's implicit beliefs about ability and adoption of different achievement goals before and after encountering failure on a golf putting task. Second, we investigated the differences in affective outcomes between entity and incremental theorists following failure feedback. Third, we examined the attributions for failure given by entity and incremental theorists. Finally, we assessed whether entity and incremental theorists differed in their willingness to participate in an introductory golf training programme following their performance on the golf putting task.

Specifically, the following hypotheses were formulated:

1. An entity belief will lead to the adoption of a performance goal and an incremental belief will lead to a learning goal, either before or after experiencing failure. 
2. After failure feedback, entity theorists will report more negative affect and less enjoyment compared to incremental theorists.

3. Entity theorists will attribute failure more to ability than effort when compared to incremental theorists. Conversely, incremental theorists will attribute failure more to effort than ability.

4. Entity theorists will be less likely to take the opportunity of participating in a golf training programme compared to incremental theorists following their 'poor' performance on the putting task.

Although the main focus of the present study was on the theoretical propositions detailed above, we were also interested to see whether self-theories of ability interact with gender to determine cognitive, affective and behavioural outcomes. Accordingly, gender was included in the analyses as an independent variable alongside experimental condition.

\section{Method}

\section{Participants}

The sample comprised 123 secondary school students (54 males, 69 females) from one school in the English Midlands. The students ranged in age from 11 to 15 years (mean $=13.40$ years, $\mathrm{SD}=1.18$ ).

\section{Procedures}

The experimental sessions were conducted during normal school physical education lessons whereby the teachers sent one student at a time to the researchers to take part in the experimental task. A quiet room near the gymnasium was used to house the sport equipment, a table, and a chair. A golf putting task was chosen as the sport activity. The objective for each participant was to putt a golf ball into a hole from different distances on a 3-m putting strip comprising an artificial grass mat. Level 1 was $1 \mathrm{~m}$ away from the hole, and Level 5 was $3 \mathrm{~m}$ away from the hole. Each level was $0.5 \mathrm{~m}$ apart. Before the manipulation of beliefs, each participant was given 10 familiarisation trials to putt on the mat with no hole. The experiment complied with ethical principles of the British Psychological Society with all participants being carefully debriefed following trials.

\section{Manipulation of beliefs}

Equal numbers of participants were randomly assigned to one of three groups: entity belief manipulation, incremental belief manipulation, or a control group with no belief manipulation.

\section{Entity belief manipulation}

In the entity condition, participants were told that the purpose of the task was to take part in a 'Talent Identification Scheme' for a well-known university that aimed to identify young talent in golf. In addition, the participants were told that: 
Research studies have shown that people are born with certain potential ability (or talent) required for certain sports and it is difficult to change that ability. Skills can be improved through learning and training but ability cannot change. Take golf, for example-Tiger Woods was only 19-yearsold when he won the US Masters. Clearly, he is naturally gifted. Golf putting, in particular, requires high abilities in terms of accuracy, co-ordination, and spatial awareness in order to do well at a high level. It is difficult to change those abilities even with training and practice. Some people are just better than others.

After these instructions, the participants were invited to take part in the putting ability test in order to identify talented golfers.

\section{Incremental belief manipulation}

In the incremental condition, participants were told that the purpose of the session was to introduce golf putting. In addition, they were told:

Research studies have shown that people develop their sport abilities through learning and training. Therefore, sport ability can be improved through proper training and practice. There is no such thing as born talent or genius in sport. Take golf, for example-one of the top golfers in the UK, Nick Faldo, spends at least $20 \mathrm{~h}$ per week training. Golf is a sport that requires training and practice; as long as you practise correctly, everyone can improve their golf abilities to a higher level.

After the manipulation, the participants were asked to take part in the putting exercise to find out their current level in golf. They were also told not to worry about making mistakes.

In the control condition, there was no manipulation of beliefs. The participants were asked to take part in the golf putting task and to answer some questions.

After the manipulations, the participants completed the first questionnaire (see Measures below). In the experimental trials, participants were asked to putt the ball from Level 4 (second most difficult position). They were told that the criterion was to putt 4 out of 10 balls into the hole. The standard was set artificially high in anticipation that no participant would surpass it. Using this procedure, three students were eliminated because they scored 4 or higher.

After the trials, the participants in all three conditions were given failure feedback. They were told that they did very badly in the trials compared to the average standard for children of their age. Participants were then asked to complete the second questionnaire (see Measures below). Upon completion of the second questionnaire, the experimenter apologised to the participants that there was not enough time for them to continue and that the introduction to golf putting (incremental condition) or test (entity condition) was finished.

\section{Measures}

The first questionnaire contained items measuring participants' beliefs about ability in golf, their perceived competence in golf and their adoption of performance and learning goals before encountering failure. Measuring participants' beliefs and perceived competence allowed us to gauge the effectiveness of the manipulation procedures and to establish that all groups were similar in terms of perceived golf 
competence. All items in the first questionnaire were measured on 6-point scales ranging from 1 (strongly disagree or not at all) to 6 (strongly agree or very much so).

\section{Implicit beliefs about golf ability}

Four items from the CNAAQ-2 (Biddle et al., 2003) were adapted to measure the participants' beliefs about golf ability. Two items assessed entity beliefs: "you have a certain level of golf putting ability and cannot really do much to change that level" and "to be good in golf putting you need to be naturally gifted". Two items assessed incremental beliefs: "to be successful in golf putting you need to learn techniques and skills and practise them regularly" and "how good you are in golf putting will always improve if you work at it". Mean scale scores were calculated by summing responses and dividing by the number of items.

\section{Perceived competence}

The perceived ability of the participants in golf putting was measured through two items: "I expect myself to do well in the golf putting test today" and "I expect myself to be among one of the best in the golf putting test". Scores on these two items were combined and mean scores were calculated for subsequent analysis.

\section{Goal adoption before failure feedback}

Two items assessed participants' goals. The stem was "I intend to do the golf putting test today in school...". One item measured a performance goal ('to do better than others') and one item measured a learning goal ('to learn from the golf putting test').

The second questionnaire assessed goal adoption following failure feedback, affect (tension, anxiety, happiness, enjoyment), attributions, and willingness to participate in a golf training programme. All items were measured on a 6-point scale ranging from 1 (strongly disagree or not at all) to 6 (strongly agree or very much so), with the exception of the single enjoyment item which was measured using an 11 -point scale ( -5 unenjoyable to +5 enjoyable).

\section{Goal adoption after failure feedback}

We adopted a 'task choice' measure from Dweck and Leggett (1988) as a reflection of students' achievement goals following failure feedback. Dweck and Leggett suggested that an individual's goals are embodied in their choice of different tasks. Three items assessed a performance goal: "I like to play levels that are not too hard, so I don't get bad scores" (item 1), "I like levels that are hard enough to show that I am good in golf" (item 2), and "I like levels that are fairly easy, so I will do well" (item 3). The fourth item measured a learning goal: "I like to try difficult and challenging levels so that I can try to learn from the task, even if I won't do well" (item 4). The purpose of using three items to measure a performance goal was to offset the social desirability of the learning goal (Dweck, 1999; Dweck \& Leggett, 1988). Exploratory factor analysis with varimax rotation suggested that items 2 (loading 0.74) and $4(0.88)$ loaded on the same factor and item $1(0.89)$ and item $3(0.87)$ loaded on a second factor. The total variance explained was $75.34 \%$. Therefore, items 1 and 3 were retained as measures of an omnibus performance goal, and item 4 represented a learning goal. Item 2 was dropped from further analyses. 
Affect

The participants were asked to indicate the extent to which they felt tense, anxious, and happy in taking part in the golf putting and also how much they enjoyed their participation.

\section{Attributions}

The participants' attributions for their 'poor' performance were measured through two items with the stem "I didn't do well in the golf putting test today because...". The participants were asked to indicate the degree to which their performance was due to lack of effort and to lack of ability.

\section{Behavioural marker}

We asked the participants to indicate how much they would want to join a training programme in golf putting in their school.

\section{Results}

\section{Preliminary analyses}

\section{Manipulation check and perceived competence}

The means and standard deviations of the participants' beliefs about golf ability are presented in Table 1 by condition (group) and gender. A 2 (gender) $\times 3$ (group) MANOVA was conducted with entity and incremental beliefs as dependent variables to check whether the manipulation of beliefs was successful. The results revealed a significant multivariate effect for group (Wilks' $\Lambda=0.621, F_{4,226}=$ $\left.15.17, P=0.000, \eta^{2}=0.21\right)$, however, there were no gender or interactive effects. Follow-up univariate analyses showed that significant differences existed in both incremental beliefs $\left(F_{2,114}=4.75, P<0.01\right.$, $\left.\eta^{2}=0.08\right)$ and entity beliefs $\left(F_{2,114}=30.92, P=0.000, \eta^{2}=0.35\right)$. Post hoc Tukey HSD tests found that the Incremental group had higher incremental beliefs compared to the Entity group $(P=0.001)$ but not the Control group $(P>0.05)$, and the Entity group had higher entity beliefs compared to the Incremental group $(P=0.000)$ and Control group $(P=0.000)$. In sum, these results showed that the induction of entity and incremental theories of sport ability was largely successful.

A gender $\mathrm{x}$ group ANOVA with perceived competence as the dependent variable indicated that males had higher perceived competence in golf compared to females $\left(F_{1,114}=13.32, P=0.000, \eta^{2}=0.11\right)$, but no differences were found between the three groups, nor was there a significant interaction (see Table 1 ).

Table 1

Implicit beliefs about golf ability and perceived competence (by condition and gender)

\begin{tabular}{lrrrrr}
\hline & Entity & Incremental & Control & Males & Females \\
\hline Entity beliefs & $3.54^{\mathrm{ab}}(0.71)$ & $2.04^{\mathrm{a}}(1.11)$ & $2.46^{\mathrm{b}}(0.62)$ & $2.72(0.88)$ & $2.64(0.78)$ \\
Incremental beliefs & $4.58^{\mathrm{a}}(1.04)$ & $5.24^{\mathrm{a}}(0.63)$ & $4.94^{\mathrm{b}}(0.74)$ & $5.07(0.72)$ & $4.80(0.80)$ \\
Perceived competence & $3.80(1.20)$ & $3.50(1.01)$ & $3.71(1.02)$ & $4.07^{\mathrm{a}}(1.00)$ & $3.37^{\mathrm{a}}(1.05)$ \\
\hline
\end{tabular}

Note. Means within the same row with the same superscript are significantly different $(P<0.05)$. 
Main analyses

\section{Goal adoption before failure feedback}

A gender x group MANOVA was performed on the participants' goals before encountering failure. The results revealed a non-significant trend for group (Wilks' $\Lambda=0.924, F_{4,226}=2.27, P=0.062, \eta^{2}=$ 0.04). Follow-up ANOVAs indicated that the groups differed in adopting performance goals $\left(F_{2,114}=\right.$ 4.38, $P=0.015, \eta^{2}=0.07$ ) with the Entity group having a greater intention to do better than others compared to the Incremental group $(P=0.045)$ but not the Control group $(P>0.05)$. All three groups adopted high learning goals for the golf putting task $(P>0.05)$. Significant gender differences were found (Wilks' $\Lambda=0.906, F_{2,113}=5.89, P=0.004, \eta^{2}=0.09$ ) such that boys were more likely to adopt learning goals than girls $\left(F_{1,114}=10.03, P=0.002, \eta^{2}=0.08\right)$. No interaction effect was observed (see Table 2).

\section{Goal adoption following failure feedback}

A gender x group MANOVA revealed a significant main effect for group (Wilks' $\Lambda=0.82, F_{4,226}=$ $6.01, P<0.001, \eta^{2}=0.10$ ) but no effect for gender or interaction. Follow-up ANOVAs revealed that the groups differed in the adoption of both learning $\left(F_{2,114}=3.23, P=0.043, \eta^{2}=0.05\right)$ and performance goals $\left(F_{2,114}=10.41, P<0.001, \eta^{2}=0.15\right)$. Post hoc Tukey HSD tests indicated that the Incremental group was more likely to adopt learning goals than the Entity group $(P=0.028)$ but not the Control group $(P>0.05)$, whereas the Entity group was more likely to adopt performance goals than the Incremental group $(P=0.000)$ and the Control group $(P=0.009)$ (see Table 2$)$.

In sum, the results suggest that fixed conceptions of sport ability are more likely to orient the participants to performance goals and incremental conceptions of sport ability lead to the adoption of learning goals. This supports Hypothesis 1 . In addition, the causal link between beliefs and goal adoption appears more evident when the participants are faced with adversity. Moreover, there were no gender differences in the adoption of goals in the three conditions when faced with setbacks, although males were more likely to adopt learning goals than females before they received failure feedback.

\section{Affective measures}

A gender $x$ group MANOVA showed no significant differences between the three groups or an interactive effect on the affective measures (tension, anxiety, happiness, and enjoyment). However, a significant main effect was found for gender (Wilks' $\Lambda=0.821, F_{4,109}=5.95, P=0.000, \eta^{2}=0.18$ ) with males more anxious than females $(P=0.048)$ but also reporting higher enjoyment $(p=0.000)$.

Table 2

Goal adoption before and after failure feedback (by condition and gender)

\begin{tabular}{lrrrrr}
\hline & Entity & Incremental & Control & Males & Females \\
\hline Before failure feedback & & & & & \\
Performance goal & $3.25^{\mathrm{a}}(1.46)$ & $2.48^{\mathrm{a}}(1.52)$ & $2.60^{\mathrm{b}}(1.34)$ & $3.04(1.53)$ & $2.63(1.34)$ \\
Learning goal & $4.70(1.24)$ & $4.60(1.37)$ & $4.70(1.16)$ & $5.09^{\mathrm{a}}(0.87)$ & $4.36^{\mathrm{a}}(1.39)$ \\
After failure feedback & & & & \\
Performance goal & $4.74^{\mathrm{ab}}(0.91)$ & $3.51^{\mathrm{a}}(1.29)$ & $4.00^{\mathrm{b}}(1.09)$ & $3.88(1.01)$ & $4.21(1.15)$ \\
Learning goal & $3.83^{\mathrm{a}}(1.30)$ & $4.55^{\mathrm{a}}(1.24)$ & $3.90^{\mathrm{b}}(1.22)$ & $4.34(1.19)$ & $3.93(1.29)$ \\
\hline
\end{tabular}

Note. Means within the same row with the same superscript are significantly different $(P<0.05)$. 
Table 3

Attributions, affect and behavioural marker after failure feedback (by condition and gender)

\begin{tabular}{|c|c|c|c|c|c|}
\hline & Entity & Incremental & Control & Males & Females \\
\hline \multicolumn{6}{|l|}{ Attributions } \\
\hline Ability & $4.23^{\mathrm{ab}}(1.29)$ & $3.54^{\mathrm{a}}(1.24)$ & $3.44^{\mathrm{b}}(1.16)$ & $3.64(1.15)$ & $3.82(1.31)$ \\
\hline Effort & $3.00(1.24)$ & $2.78(1.33)$ & $2.73(1.09)$ & $2.67(1.26)$ & $2.96(1.18)$ \\
\hline \multicolumn{6}{|l|}{ Affect } \\
\hline Enjoyment & $2.46(2.19)$ & $2.75(1.92)$ & $2.82(1.60)$ & $3.42^{\mathrm{a}}(1.62)$ & $2.11^{\mathrm{a}}(1.93)$ \\
\hline Happiness & $3.62(1.46)$ & $3.55(1.40)$ & $3.31(1.26)$ & $3.63(1.43)$ & $3.39(1.33)$ \\
\hline Tension & $3.33(1.58)$ & $2.80(1.38)$ & $3.23(1.18)$ & $2.86(1.40)$ & $3.31(1.37)$ \\
\hline Anxiety & $3.31(1.47)$ & $3.23(1.46)$ & $3.05(1.34)$ & $3.47^{\mathrm{a}}(1.55)$ & $2.99^{\mathrm{a}}(1.27)$ \\
\hline \multicolumn{6}{|l|}{ Behavioural marker } \\
\hline Training programme & $3.88(1.59)$ & $3.73(1.57)$ & $3.45(1.50)$ & $4.44^{\mathrm{a}}(1.13)$ & $3.10^{\mathrm{a}}(1.58)$ \\
\hline
\end{tabular}

Note. Means within the same row with the same superscript are significantly different $(P<0.05)$.

The findings do not support Hypothesis 2. All groups reported only moderate levels of anxiety and tension but moderately high positive affect (see Table 3). The experimental context appeared not to be sufficiently powerful to influence affective responses in the expected direction.

\section{Attributions after failure}

A gender $\mathrm{x}$ group MANOVA was conducted with ability and effort attributions as dependent variables. As predicted, there was a significant main effect for group (Wilks' $\Lambda=0.912, F_{4,226}=2.37$, $\left.P=0.05, \eta^{2}=0.04\right)$. Further analyses revealed that the three groups differed on ability but not effort attributions $\left(F_{2,114}=4.80, P=0.010, \eta^{2}=0.08\right)$. Specifically, Entity theorists made significantly stronger ability attributions than Incremental theorists $(P=0.04)$ and the Control group $(P=0.015)$ (see Table 3 ). There were no gender or interactive effects. Hypothesis 3 was, therefore, supported for ability attributions only. Most participants were, generally, high on incremental beliefs regardless of the experimental manipulation, which probably accounted for the similar scores in effort attributions across groups.

\section{Behavioural marker}

A gender x group ANOVA revealed a significant main effect for gender $\left(F_{1,114}=27.61, P=0.000\right.$, $\left.\eta^{2}=0.20\right)$ but no group or interactive effects. Males were more likely than females to want to take part in a golf putting programme in the future (see Table 3). Hypothesis 4 is, therefore, rejected. Again, high levels of incremental beliefs may make it difficult to find meaningful differences between the two belief conditions.

\section{Discussion}

The experiment has shown that sport ability beliefs can be experimentally manipulated. Support was found for a causal link between self-theories of ability and goals (Hypothesis (H)1). In addition, ability attributions for failure were stronger for entity theorists (H3). However, hypotheses predicting differences on effort attributions (H3), affective reactions $(\mathrm{H} 2)$, and an index of behaviour (H4) were not 
supported. Although certain gender differences on these measures emerged, the influence of gender proved to be independent of experimental condition, and no interactive effects between gender and selftheories of ability were found.

Self-theories of ability have not been researched extensively in sport, and to our knowledge, the present investigation represents one of the first attempts to manipulate such beliefs in young people. We found that, although experimentally inducing entity and incremental ability beliefs was possible, all participants were quite strongly predisposed toward incremental beliefs. This latter point most likely accounts for the non-significant findings which emerged. We succeeded in terms of differentiating both incremental and entity beliefs among the two experimental groups, however, the control and incremental groups did not differ in terms of incremental beliefs. Thus, the manipulation of incremental beliefs via the reading passage was not sufficiently compelling to distinguish participants in this condition from those in the control condition.

Consequently, in the present research, comparisons were made between high entity-high incremental and low entity-high incremental youth. This suggests that future studies might explore the possibility of screening participants in order to sample those low in incremental beliefs. In this way, similar to testing for achievement goal profiles (Fox, Goudas, Biddle, Duda, \& Armstrong, 1994), one could test different belief profiles. Wang and Biddle (2001), for example, found that one highly motivated group in their cluster analysis of motivation variables contained young people high in both incremental and entity beliefs whereas the least motivated group contained youth low in incremental and high in entity beliefs, at least compared to others in the sample. The present findings, therefore question Dweck et al.'s (1995b) assertion that individuals tend to have a dominant implicit theory in a specific domain. In sport, at least, it seems likely that youth can and do endorse both entity and incremental beliefs.

The choice of sports performer referred to in the reading passage is likely to be a key factor in determining the efficacy of the beliefs manipulation. Tiger Woods and Nick Faldo may not have been the most appropriate performers to influence the beliefs of the participants, particularly those less familiar with golf. The familiarity and impact of the 'role model' used in the manipulation is therefore an important consideration for future research. Young children are not likely to be persuaded by the presentation of ('fictitious') scientific research findings to induce their entity and incremental beliefs (often utilised in studies involving undergraduate students as participants). Further studies of this sort should utilise the same role model in both incremental and entity conditions to avoid a possible confound. The delivery of the manipulation through video using well-known performers, rather than a written passage, may also provide a more compelling message. Moreover, reference to ' $20 \mathrm{~h}$ per week training' in the incremental condition may need to be revised upwards to convey adequately the role of hard work and effort in bringing about improvements in ability. These changes in the way that selftheories of sport ability are induced should enable researchers to separate experimental from control groups, particularly with regard to incremental beliefs.

With respect to the physical task employed in future work, investigators should seek to utilise tasks that both male and female students value, tasks in which participants are experienced, as well as tasks such as gymnastic movements for which young people are less likely to endorse an incremental theory and more likely to endorse an entity theory (Spray \& Warburton, 2003). Evidence from the current study suggested that male students valued the golf putting task more highly, and perceived themselves as more competent at golf putting, in comparison to female students. The novelty of the putting task, along with the minimal physical effort involved in such an activity, may also help to explain the high incremental beliefs found among all participants. 
Theoretical propositions state that differences between entity and incremental theorists in achievement-related affect and behaviour will be most apparent under conditions of adversity (Dweck, 1999). However, we suggest that the effectiveness and ecological validity of the negative feedback used in the present investigation can be enhanced in future studies. Each participant received negative feedback on one occasion during their golf putting trial, and it can be questioned whether this is sufficient to influence the participant's perception of their performance, and to impact on the outcomes under consideration. In school physical education, for example, individuals may be exposed repeatedly to this type of information over the course of a unit of work. Future field experimental research, operating within ethical boundaries, should consider the type, frequency, timing, clarity, and meaningfulness of the negative feedback provided. For example, we need to ensure, with respect to the timing of the negative feedback and the measurement of enjoyment, that participants respond to their feelings of enjoyment toward the task and not provide their reaction to the feedback per se.

Although the induction of entity beliefs was associated with greater use of ability attributions, other cognitive and affective measures did not differ between the experimental groups. A behavioural marker was similarly unaffected. This suggests that the high incremental beliefs of both groups might offset some potentially negative influences of entity beliefs. Similar to goal orientations, where a high ego orientation is motivationally positive when accompanied with a high task orientation, so it seems with incremental and entity beliefs. Further research efforts are required to establish which adaptive and maladaptive motivational processes and outcomes are associated with different belief profiles.

In the present study, despite all participants being quite high in incremental beliefs, the achievement goals adopted for the golf task were influenced by ability beliefs, particularly following failure. This is consistent with Dweck's (1999) theorising. The causal influence of ability beliefs on the formation of different goals does not preclude the possibility, however, that experimentally manipulating achievement goals would lead to the activation of different ability beliefs. Goals, beliefs and motivational responses all constitute interrelated structures and eliciting one variable should lead to eliciting other variables within this framework (Dweck et al., 1995b). These notions require testing in the sport domain and beyond.

Ability beliefs form an important piece in the larger jigsaw of youth physical activity motivation but one that requires further clarification in relation to the observation that many young people hold high incremental beliefs. Dweck and colleagues have noted in their research programme that participants who reject entity beliefs in a specific domain invariably offer alternative incremental-based beliefs (Dweck, 1999; Dweck et al., 1995b). However, future research might consider whether youth believe that sport ability is incremental but only within small limits of natural ability, whereas others might believe that greater change in ability is possible. It is also important to study self-theories of ability further because it is not fully understood whether incremental beliefs always lead to adaptive outcomes and entity beliefs always lead to maladaptive outcomes (Dweck et al., 1995b). The limited correlational research in physical settings points toward the adaptive impact of holding incremental beliefs, but experimental and longitudinal designs are needed to substantiate these findings. It may be that entity beliefs are not universally maladaptive, and in some contexts and for some individuals, lead to adaptive outcomes. The influence of ability beliefs on performance, particularly when faced with setbacks, should be a focal concern of future investigations. In addition, research in the physical domain should delineate more explicitly the links between self-theories of ability and both approach and avoidance forms of achievement goals (see Cury et al., 2002; Elliot, 1999). There remains a great deal of research to be 
conducted into individuals' theories of ability and we believe that this work will help to shed light on important motivational processes in youth sport.

\section{References}

Biddle, S. J. H. (1997). Current trends in sport and exercise psychology research. The Psychologist: Bulletin of the British Psychological Society, 10, 63-69.

Biddle, S. J. H., Soos, I., \& Chatzisarantis, N. (1999). Predicting physical activity intentions using a goal perspectives approach: A study of Hungarian youth. Scandinavian Journal of Medicine and Science in Sports, 9, 353-357.

Biddle, S. J. H., Wang, C. K. J., Chatzisarantis, N. L. D., \& Spray, C. M. (2003). Motivation for physical activity in young people: Entity and incremental beliefs concerning athletic ability. Journal of Sports Sciences, 21, 973-989.

Cury, F., Da Fonseca, D., Rufo, M., \& Sarrazin, P. (2002). Perceptions of competence, implicit theory of ability, perception of motivational climate, and achievement goals: A test of the trichotomous conceptualization of endorsement of achievement motivation in the physical education setting. Perceptual and Motor Skills, 95, 233-244.

Duda, J.L. (2001). Achievement goal research in sport: Pushing the boundaries and clarifying some misunderstandings. In G.C. Roberts (Ed.) Advances in motivation in sport and exercise (pp. 129-182). Champaign, IL: Human Kinetics.

Duda, J.L., \& Hall, H. (2001). Achievement goal theory in sport: Recent extensions and future directions. In R.N. Singer, H.A. Hausenblas \& C.M. Janelle (Eds.) Handbook of sport psychology (pp. 417-443). New York: Wiley.

Dweck, C.S. (1999). Self-theories: Their role in motivation, personality, and development. Philadelphia, PA: Taylor \& Francis.

Dweck, C. S., Chiu, C., \& Hong, Y. (1995a). Implicit theories and their role in judgments and reactions: A world from two perspectives. Psychological Inquiry, 6, 267-285.

Dweck, C. S., Chiu, C., \& Hong, Y. (1995b). Implicit theories: Elaboration and extension of the model. Psychological Inquiry, 6, 322-333.

Dweck, C.S., \& Elliott, E.S. (1983). Achievement motivation. In E.M. Hetherington (Ed.) Handbook of child psychology: Socialization, personality and social development (pp. 643-691). New York: Wiley.

Dweck, C. S., \& Leggett, E. L. (1988). A social-cognitive approach to motivation and personality. Psychological Review, 95, 256-273.

Elliot, A. J. (1999). Approach and avoidance motivation and achievement goals. Educational Psychologist, 34, 169-189.

Fox, K., Goudas, M., Biddle, S., Duda, J., \& Armstrong, N. (1994). Children's task and ego goal profiles in sport. British Journal of Educational Psychology, 64, 253-261.

Franiuk, R., Cohen, D., \& Pomerantz, E. M. (2002). Implicit theories of relationships: Implications for relationship satisfaction and longevity. Personal Relationships, 9, 345-367.

Hong, Y., Chiu, C., Dweck, C. S., Lin, D. M., \& Wan, W. (1999). Implicit theories, attributions, and coping: A meaning system approach. Journal of Personality and Social Psychology, 77, 588-599.

Jourden, F., Bandura, A., \& Banfield, J. T. (1991). The impact of conceptions of ability on self-regulatory factors and motor skill acquisition. Journal of Sport \& Exercise Psychology, 13, 213-226.

Kasimatis, M., Miller, M., \& Macussen, L. (1996). The effects of implicit theories on exercise motivation. Journal of Research in Personality, 30, 510-516.

Levy, S. R., \& Dweck, C. S. (1998). Trait- versus process-focused social judgment. Social Cognition, 16, 151-172.

Levy, S. R., Stroessner, S. J., \& Dweck, C. S. (1998). Stereotype formation and endorsement: The role of implicit theories. Journal of Personality and Social Psychology, 74, 1421-1436.

Lintunen, T., Valkonen, A., Leskinen, E., \& Biddle, S. J. H. (1999). Predicting physical activity intentions using a goal perspectives approach: A study of Finnish youth. Scandinavian Journal of Medicine and Science in Sports, 9, 344-352.

McConnell, A. R. (2001). Implicit theories: Consequences for social judgments of individuals. Journal of Experimental Social Psychology, 37, 215-227.

Ommundsen, Y. (2001). Pupils' affective responses in physical education classes: The association of implicit theories of the nature of ability and achievement goals. European Physical Education Review, 7, 219-242.

Ommundsen, Y. (2001). Self-handicapping strategies in physical education classes: the influence of implicit theories of the nature of ability and achievement goal orientations. Psychology of Sport and Exercise, 2, 139-156. 
Plaks, J. E., Stroessner, S. J., Dweck, C. S., \& Sherman, J. W. (2001). Person theories and attention allocation: Preferences for stereotypic versus counterstereotypic information. Journal of Personality and Social Psychology, 80, 876-893.

Roberts, G.C. (1992). Motivation in sport and exercise: Conceptual constraints and convergence. In G.C. Roberts (Ed.) Motivation in sport and exercise (pp. 3-29). Champaign, IL: Human Kinetics.

Roberts, G.C. (Ed.). (2001). Advances in motivation in sport and exercise. Champaign, IL: Human Kinetics.

Sarrazin, P., Biddle, S., Famose, J. P., Cury, F., Fox, K., \& Durand, M. (1996). Goal orientations and conceptions of the nature of sport ability in children: A social cognitive approach. British Journal of Social Psychology, 35, 399-414.

Spinath, B., Spinath, F. M., Riemann, R., \& Angleitner, A. (2003). Implicit theories about personality and intelligence and their relationship to actual personality and intelligence. Personality and Individual Differences, 35, 939-951.

Spray, C.M. \& Warburton, V.E. (2003). Ability beliefs, achievement goals, and motivation in physical education classes. In R. Stelter (Ed.) New approaches to exercise and sport psychology: Theories, methods and applications. Proceedings of the 11th European congress of sport psychology. (p. 160). Copenhagen, Denmark: FEPSAC.

Wang, C. K. J., \& Biddle, S. J. H. (2001). Young people's motivational profiles in physical activity: A cluster analysis. Journal of Sport and Exercise Psychology, 23, 1-22.

Weiner, B. (1992). Human motivation. Newbury Park, CA: Sage. 